\title{
Home Lighting: A Challenge to Improve and Standardise
}

\begin{abstract}
Investigation presented in the paper aims to map the current situation in home lighting in order to acquire an imagination on preferences and solutions applied by end users - inhabitants, by means of available technologies and taking into account the inheritage of existing systems as well as habits of mind. Besides qualitative findings, quantitative assessment of lighting performance and estimation of energy performance is in the focus of investigation as well. Assumption of the investigation relies on the fact that what is installed in homes for lighting, selected, arranged and installed by the user, is felt by the user as illumination satisfying his needs in all aspects (aesthetic function, lighting control etc.).

Questionaire is selected as the method of investigation. To achieve the needed level of reliability of data and because measurements of the illuminance are needed, the questionaire is to be completed by a professional investigator. The questionaire-based investigation is expected to provide a vast of useful information on home lighting. The paper is aimed to present the method which can be applied worldwide and to publish the results of analyses performed over data acquired on national level. Results of investigation are intended to be used for the standardization of home lighting requirements and the preparation of guidelines based on good lighting practice.
\end{abstract}

Keywords: home lighting, interior lighting, atmospheric lighting, residential buildings, lighting standardisation

\section{Introduction}

For home lighting, neither $\mathrm{CIE}$ recommendation nor international standard is available. Designing and installation of a lighting system is let to the user as a part of furbishment. To help the public become familiar with current technologies and to help them how to choose the right luminaires and arrange them in the space or outdoors, numerous guideliness are provided e.g. by national lighting societies or often by electrical utility companies. However, impact is too low and inhabitants make the lighting on their own. The guidelines, though usually prepared by professionals, lack for discussed and agreed light levels and lighting solutions. In consequence:

- Designer of electrical installation has no tool how to place lighting outlets, what wattage to consider and what other technical measures are needed (i.e. to have builtin boxes for transformers or LED drivers). Customer has no imagination about these technical questions, he is unable to estimate what light level will be sufficient and how to satisfy it.

- There are no benchmarks and no method how to estimate the annual energy consumption of lighting system in homes.

- Users lack for advice on selection of proper lamps and luminaires and shopping assistants are lost in questioning, as reported by shop owners, particular about LEDs. In the era of the raise of compact fluorescent lamps as energy efficient alternatives to incandescent lamps users were often disappointed by the result of lighting as luminous flux distribution was different than from bulbs. LEDs are yet more different intensive point sources of light can easily glare and light colour of the cheap products is simply unpleasant. Wattage is another serious problem: until incandescents have been phased out, in shops there were three shelves side by side, with 60 - 100 W GSLs, $11-23$ W CFLs and $1-7 \mathrm{~W}$ LEDs with the same universal E14/E27 bases. Of course, evocation of piece-for-piece equivalence for the replacement is evident.

Aim of standardization is not to give prescriptions or restrictions but to record the current level of knowledge and to provide requirements for proper lighting of homes. Solution itself, can incorporate the artistic vision and the same time to create a certain level of illumination. As the starting point, older national standards can be reviewed and possibly updated or reworked. Such a standard on home lighting is available in Slovakia - STN 360452 „Artificial Lighting of Residential Buildings“.
NOTE In Slovakia there is also a standard on daylighting of residential buildings STN $730580-2$, but this is out of the scope of this paper.

Importance of normative status in this field increased since privat houses and residential buildings are subjected to the energy performance of buildings according to the European directive where lighting is one of the four components under assessment. But for now, due to lack of a relevant standard, these building categories are excluded from the process. The new draft of European standard on energy performance of lighting in buildings prEN 15193-1 in its last known version deals with the topic, and objectives incorporate, amongst others, also home lighting issues. Draft technical report TR 15193-2 brings some additional guidelines for homelighting. It means that normative requirements are included in Part 1 while guidelines are dealt in Part 2. Based on the European standard, an international standard has been prepared in technical committee CIE/TC3-52 and now a new workgroup WG1 has been actually also etablished and started working in ISO/TC274. This working group acts jointly with the new CIE/JTC6 and the former committee CIE/TC3-52 is dissolved.

Home lighting should not be excepted from assessment of energy perfomance of residential buildings, thus extension of the relevant standards by e.g. standard annual operation time, installed power in different kinds of rooms and useful area of these rooms, is meaningful. Energy performance should be supported by requirements to quantitative and qualitative photometric parameters including illuminance and uniformity of illuminance while recommendations how to arrange the lighting systems should be the subject of a technical report or a guideline.

\section{Background}

The standard STN 360452 is applicable for illumination of residential buildings of all types. It specifies requirements for lighting with respect to the creation of healthy environment.

Lighting systems can be constructed or re-constructed only in accordance with the approved project documentation except of lighting which is not part of the building design. Home lighting project shall consider the functional utilization of rooms and designed disposition of interior furniture. 
NOTE Requirement for preparation of lighting design documentation is essential and sets the home lighting to the leve of e.g. workplace lighting. In the current practice, such documentation is normally not provided by any professional, except of rare sophisticated installations.

Ratio of the average illuminance from general or localized lighting between neighbouring rooms that have a functional relationship shall not be less than $0,2(1: 5)$ and for areas with occasional usage $0,1(1: 10)$.

Limits of the glare rating index $G_{\mathrm{N}}$ for different activities are tabelized in the standard.

NOTE The glare rating index $G_{\mathrm{N}}$ relates to the withdrawn generic standard STN 360450 and as such it is outdated. For the update it should be substituted by UGR.

Visual performance, visual comfort and avoidance of fatigue depend on luminances and their distribution in the visual field which shall be safeguarded by appropriate illuminance distribution on surfaces as well as their reflectance. Selection of reflectance and color of surfaces shall be carried out with respect to lighting requirements as well as architecture of the space and artistic solution of the interior furniture.

Due to favourable colour rendering of the skin, in living spaces lamps with warm colour appearance ( $T_{\mathrm{C}}$ less than Table 1. Benchmark values of illuminances in residential buildings according to the draft standard prEN 15193-1

\begin{tabular}{|c|c|l|l|}
\hline $\begin{array}{c}E_{\mathrm{m}}(\mathrm{Ix}) \\
\text { general }\end{array}$ & $\begin{array}{c}E_{\mathrm{m}}(\mathrm{Ix}) \\
\text { local }\end{array}$ & \multicolumn{1}{|c|}{ Premises and activities } & Local places \\
\hline 150 & 300 & Kitchen & Worktop lighting \\
\hline 150 & 300 & Dining room & Rining table \\
\hline 150 & 300 & Living room & Mirror \\
\hline 100 & 300 & Bathroom and toilet & Bedside lamps, desk lamps \\
\hline 100 & 300 & Bedroom & \\
\hline 100 & & Entrance hall, corridor, stairs & \\
\hline 200 & & Storeroom, cellar, laundry & \\
\hline
\end{tabular}

Table 2 benchmarks the installed power of lighting systems in different kinds of rooms for standard lighting solutions and for general lighting only. Values for local lighting and for optimized lighting solutions are also presented in the draft
$3300 \mathrm{~K})$ shall be used regardless on the illuminance level. For atmospheric lighting, colour temperature of lamps shall respect the artistic intention.

In living spaces for inhabitants of ethnic groups with different skin colour, lamps with intermedaite or cool colour appearance are preferrably used for the same reason.

Lamps with different colour temperature can be used in the same room only if technical and artistic solution can satisfy that the resulting composition of luminances and light colour is perceived, and that light sources with different colour temperature cannot be observed separately at the same time.

The draft standard prEN 15193-1 does not establish any requirements or recommendation to the maintained illuminance rather benchmarks this parameter. Values according to the norm prEN 15193-1 for standard lighting solutions (assumed overall efficacy $15 \mathrm{Im} / \mathrm{W}$ ) are shown in Table 1. Optimized lighting solutions assume with the overall luminous efficacy $60 \mathrm{Im} / \mathrm{W}$ and the corresponding values are around one third of the values for standard solutions. standard EN 15193-1 but not shown in this paper. Room size is categorized to three levels as it follows from Table 2.

Table 2. Benchmark values of useful area and installed power in residential buildings for general and ambient lighting and taking into account standard lighting solution, according to the draft standard prEN 15193-1

\begin{tabular}{|l|c|c|c|c|c|c|}
\hline \multirow{2}{*}{\multicolumn{2}{c}{ Premises }} & \multicolumn{3}{c|}{ Useful area $\left(\mathrm{m}^{2}\right)$} & \multicolumn{3}{c|}{ Installed power $(\mathrm{W})$} \\
\cline { 2 - 7 } & $\begin{array}{c}\text { Small } \\
\text { room }\end{array}$ & $\begin{array}{c}\text { Medium } \\
\text { room }\end{array}$ & $\begin{array}{c}\text { Large } \\
\text { room }\end{array}$ & $\begin{array}{c}\text { Small } \\
\text { room }\end{array}$ & $\begin{array}{c}\text { Medium } \\
\text { room }\end{array}$ & $\begin{array}{c}\text { Large } \\
\text { room }\end{array}$ \\
\hline Kitchen & $6-8$ & $8-10$ & $10-12$ & 60 & 80 & 120 \\
\hline Dining room & $8-12$ & $12-16$ & $16-20$ & 100 & 135 & 200 \\
\hline Living room & $8-12$ & $12-16$ & $16-20$ & 100 & 135 & 200 \\
\hline Bathroom and toilet & $4-6$ & $6-8$ & $8-10$ & 50 & 70 & 100 \\
\hline Bedroom & $6-8$ & $8-12$ & $12-16$ & 90 & 110 & 140 \\
\hline Entrance hall, corridor, stairs & $1-3$ & $3-5$ & $5-7$ & 40 & 60 & 80 \\
\hline Storeroom, cellar, laundry & $4-6$ & $6-8$ & $8-10$ & 60 & 80 & 120 \\
\hline
\end{tabular}

\section{Goals and methods of investigation}

Investigation aims to map the current situation in home lighting in Slovakia in order to acquire an imagination on preferences and solutions applied by end users inhabitants by means of available technologies and taking into account the inheritage of existing systems as well as habits of mind. Besides qualitative findings, quantitative 
Questionaire is selected as the method of investigation. To achieve the needed level of reliability of data and because measurements of the illuminance are needed, the questionaire is to be completed by a professional investigator. Target number of homes for investigation is stated to be at least 150 . Homes are distributed evenly throughout the country.

Privat houses and flats in residential buildings are distinguished by different types of questionaire due to significant difference in situation and size. In the questionaire, emphasize on accuracy of specific information is given while some other information is neglected and/or simplified for the sake of time and effort savings, to enable the completion of questionaire feasible.

Data from individual questionaires, numbered and identified by an unique ID, will be automatically read up by an application to excel sheet where data will be evaluated first type by type, then in correlations.

Photo documentation may help to imagine the situation and lighting solution, therefore investigators are requested to take pictures. However, due to obvious privacy reasons this is not mandatory.
Results of the investigation are intended to be used as an input for future standardization works in order to establish new normative requirements to home lighting and also to elaborate requirements for assessment of energy performance of home lighting within EN 15193 or national prescriptions.

Example of a questionaire (truncated excerpt) for flats in residential buildings is shown in Figure 1. Description to some abbreviations or information types is given below the Figure. Points of the measurement of illuminance for general lighting and local lighting are exactly specified for each of the rooms.

The questionaire comprise these pre-defined and fixed (to ease the evaluation) type of rooms:

- Houses: living room, bedroom, kids room, 3x rooms of a family member, kitchen, dining room, $2 x$ bathroom, $2 x$ WC, hall, $2 x$ corridor, larder, cellar, chamber, stairs, attic, garage, veranda, other

- Flats: living room, bedroom, kids room, $2 x$ rooms of a family member, kitchen, dining room, bathroom, WC, corridor, larder, cellar, stairs, other

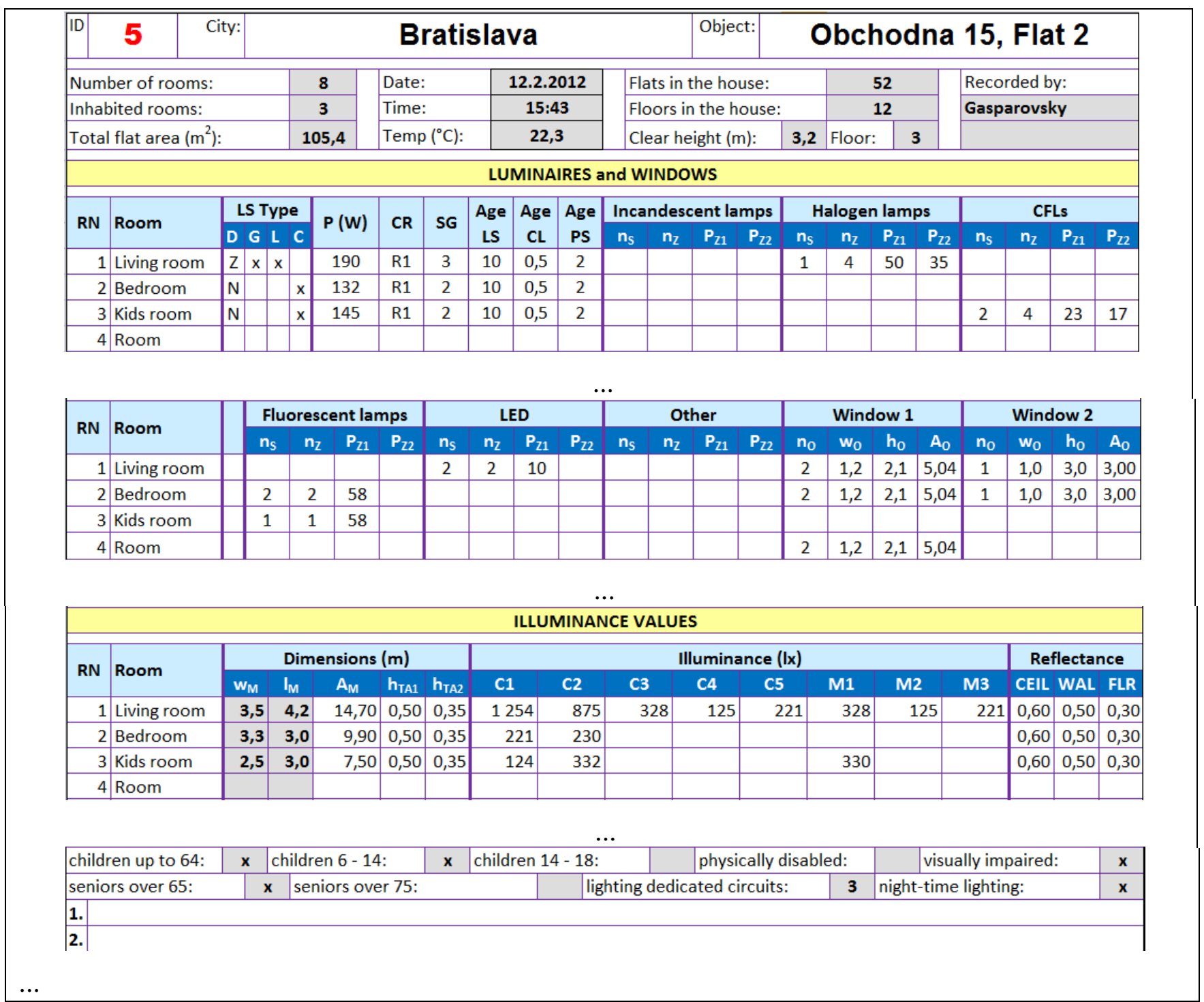

Fig.1. Questionaire for mapping the home lighting in flats of residential buildings 
Key:

LS type: Type of the lighting system

D $\mathrm{D}=$ direct, $\mathrm{S}=$ semi-direct $(40-60 \%), \mathrm{I}=$ indirect

G General lighting ( $\mathrm{x}$ )

L Local lighting $(x)$

C Localized lighting $(\mathrm{x})$

NOTE With localized lighting the function of general lighting and local lighting is provided by the same lighting system. If there are different lighting systems in a room for general and local lighting, " $\mathrm{x}$ " has to be indicated in both columns $\mathrm{G}$ and $\mathrm{L}$.

$\boldsymbol{P}(\mathbf{W})$ Installed power of lighting in the room (including control gears)

CR Code of lighting control (R1 - R9) according to the national EPBD methodology

SG Number of switching groups for lighting in the room

Age LS Age of the lighting system (years)

Age CL Time elapsed from the last cleaning of luminaires (years)

Age PS Time elapsed from the last renovation (e.g. painting) of surfaces (years)

$\boldsymbol{n}_{\mathbf{s}}$ number of luminaires in the room (total of all types installed)

$n_{z}$ number of lamps in the room (total of all types in all installed luminaires)

Table 3. Measured illuminance levels in different kinds of rooms

\begin{tabular}{|c|c|c|c|c|c|}
\hline Room & Place of measurement & $E_{\min }(\mathrm{IX})$ & $E_{\max }(\mathrm{IX})$ & $E_{\mathrm{av}}(\mathrm{Ix})$ & $\sigma$ \\
\hline \multirow[t]{5}{*}{ Living room } & middle of the unobstracted part & 63 & 198 & 123,6 & 39,71 \\
\hline & edges of sofa (average) & 45 & 200 & 107,1 & 44,72 \\
\hline & middle of sofa & 40 & 205 & 111,1 & 45,51 \\
\hline & armchair & 50 & 238 & 95,9 & 49,62 \\
\hline & middle of coffee table & 72 & 212 & 122,7 & 39,47 \\
\hline \multirow[t]{5}{*}{ Bedroom } & middle of the unobstracted part & 35 & 165 & 91,0 & 46,92 \\
\hline & middle of bed & 28 & 210 & 104,7 & 54,66 \\
\hline & header of bed 1/2 (average) & 30 & 215 & 80,5 & 51,93 \\
\hline & bedside table $1 / 2$ (average) & 20 & 190 & 58,7 & 49,55 \\
\hline & middle of table/commode & 13 & 85 & 41,6 & 25,97 \\
\hline \multirow[t]{4}{*}{ Inhabited room } & middle of the unobstracted part & 38 & 280 & 133,4 & 66,57 \\
\hline & middle of bed & 27 & 184 & 93,3 & 49,54 \\
\hline & header of bed & 35 & 160 & 84,7 & 35,29 \\
\hline & middle of bedside table & 30 & 207 & 107,7 & 60,29 \\
\hline \multirow[t]{5}{*}{ Kitchen } & middle of the unobstracted part & 65 & 200 & 119,4 & 44,5 \\
\hline & work desk edges (average) & 32 & 225 & 127,8 & 62,42 \\
\hline & middle of work desk & 47 & 298 & 162,7 & 83,95 \\
\hline & cooker & 25 & 122 & 70,0 & 28,41 \\
\hline & dining table & 60 & 205 & 121,3 & 43,59 \\
\hline \multirow[t]{4}{*}{ Bathroom } & middle of the unobstracted part & 52 & 190 & 114,4 & 42,47 \\
\hline & washbowl & 55 & 210 & 106,9 & 32,64 \\
\hline & midle of bath/shower-tub & 20 & 126 & 72,5 & 23,70 \\
\hline & middle of cosmetic table & 18 & 170 & 87,7 & 52,82 \\
\hline \multirow[t]{2}{*}{ Corridor } & middle of the unobstracted part & 22 & 200 & 97,7 & 47,56 \\
\hline & middle of table & 36 & 94 & 65,4 & 15,93 \\
\hline WC & middle of WC & 50 & 157 & 86,3 & 28,66 \\
\hline
\end{tabular}

$P_{\mathbf{Z 1}}$ wattage of the most frequent lamp type $(\mathrm{W})$

$P_{\mathbf{Z} 2}$ wattage of the second most frequent lamp type (W)

NOTE Data are to be presented according to the lamp type. With respect to the aim of investigation, correlation between luminaires and lamps is not essential.

$n_{0}$ number of windows of a given type in the room

wo width of the window $(\mathrm{m})$

$\boldsymbol{h}_{\mathrm{O}}$ height of the window $(\mathrm{m})$

$A_{0}$ area of the window $\left(\mathrm{m}^{2}\right)$, calculated automatically from its width and height

$w_{\mathrm{M}} \quad$ width of the room $(\mathrm{m})$

$l_{\mathrm{M}} \quad$ lenght of the room $(\mathrm{m})$

$\boldsymbol{A}_{\mathbf{M}}$ area of the room (m2), calculated automatically from its width and length

$\boldsymbol{h}_{\text {TA1 }}$ height of the reference plane $1(\mathrm{~m})$ for the point of measurement specified for each room

$\boldsymbol{h}_{\text {TA2 }}$ height of the reference plane $2(\mathrm{~m})$ for the point of measurement specified for each room

CEIL Average reflectance of ceiling (estimation)

WAL Average reflectance of walls (estimation)

FLR Average reflectance of floor (estimation) 


\section{Results and discussion}

Up to now, the feedback counts 30 questionaires for flats. Data are currently still being processed. This paper aims to publish chosen interim results on state-of-the-art of illuminance levels and installed power in different rooms. Age of the investigated lighting systems is depicted in Figure 2. In average, age of the lighting systems is between 5 to 10 years what is more than age of flats under investigation. It means that lighting is time to time being renovated.

Structure of light sources in the investigated lighting systems is in Figure 3. Compact fluorescent lamps are the major light sources with share of almost $30 \%$. It is obvious that these retrofit lamps have been becoming popular in the last decade. It is surprising that still there is big portion of classical incandescent bulbs. It can be expected that after phase-out of these lamps from the market, what already happened, their share will rapidly decrease and the lamps will be substituted by suitable retrofits. This process is ongoing and due to low price, mains voltage halogen lamps are preferred against CFLs and LEDs.

Usage of LED lamps will raise, they are more and more popular in households. Todays share of $10 \%$ is an evidence. Linear fluorescent lamps are generally not preferred for home lighting and the share over $10 \%$ in the lamp structure was not expected, hence needs some verification. Usage of linear fluorescent lamps and LEDs other than retrofits should be promoted.

Table 3 illustrates the results of illuminance measurement for general lighting in the middle of the unobstracted part and at the indicated particular places. Local lighting was the subject of measurement as well but these results are not dealt in this paper.The measured data have not been modified by the maintenance factor as it is expected that lighting systems in operation are not new, rather closer to their maintenance cycle period. Amount of data is yet not sufficient because not all room types are present in all measured households. Thus, Table 3 shows only the most common room types.
For each of the case, three highest and three lowest values have been deleted to avoid extreme peaks. The rest of data have been used to calculate the average value $E_{\mathrm{av}}$ (Ix) and the standard statistical deviation $\sigma$. Minimum and maximum illuminance values are indicated as well. It is hard to assess the measured data against normative requirements due to incoherence in the place of measurement. Approach of the investigation is more complex in this aspect.

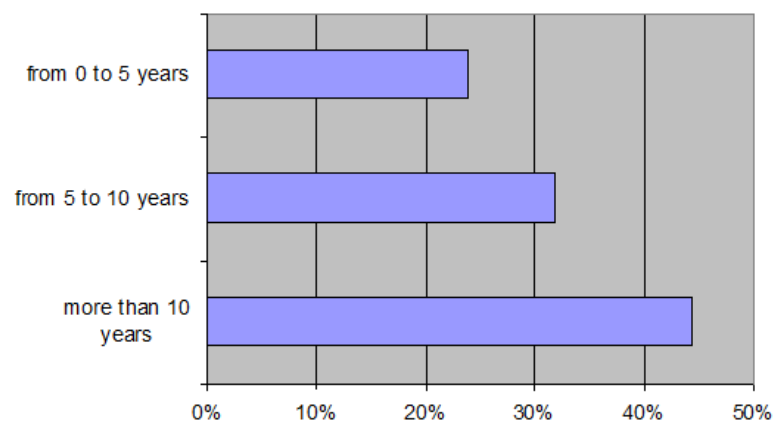

Fig.2. Age of the investigated lighting systems

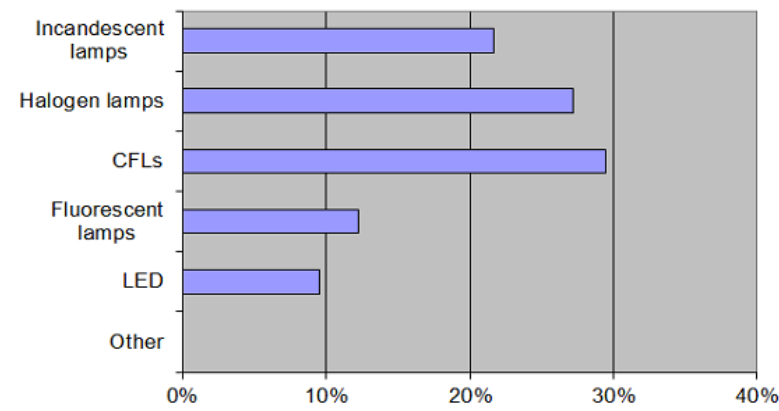

Fig.3. Structure of light sources in the investigated lighting systems

Table 4. Installed power $P(\mathrm{~W})$ and specific installed power $P / A\left(\mathrm{~W} / \mathrm{m}^{2}\right)$ in investigated residential buildings

\begin{tabular}{|l|r|r|r|r|r|r|r|r|}
\hline Rable 4. Installed power $P(\mathrm{~W})$ and specific installed power $P / A\left(\mathrm{~W} / \mathrm{m}^{2}\right)$ in investigated residential buildings \\
\hline Living room & $P_{\min }(\mathrm{W})$ & $P_{\max }(\mathrm{W})$ & $P_{\mathrm{av}}(\mathrm{W})$ & $\sigma$ & $P_{\min } / A\left(\mathrm{~W} / \mathrm{m}^{2}\right)$ & $P_{\max } / A\left(\mathrm{~W} / \mathrm{m}^{2}\right)$ & $P_{\mathrm{av}} / A\left(\mathrm{~W} / \mathrm{m}^{2}\right)$ & $\sigma$ \\
\hline Bedroom & 20 & 320 & 167,4 & 84,90 & 1,22 & 16,16 & 7,94 & 3,58 \\
\hline Kid's room & 50 & 157 & 101,3 & 35,61 & 1,43 & 13,33 & 6,54 & 3,17 \\
\hline Inhabited room & 67 & 137 & 106,3 & 45,38 & 3,38 & 12,12 & 7,68 & 2,94 \\
\hline Kitchen & 20 & 180 & 87,3 & 46,02 & 1,79 & 19,05 & 6,51 & 4,25 \\
\hline Dining room & 40 & 150 & 87,5 & 40,07 & 3,51 & 23,21 & 9,21 & 4,68 \\
\hline Bathroom & 108 & 120 & 114,0 & 53,96 & 3,86 & 12,50 & 8,18 & 4,32 \\
\hline WC & 40 & 140 & 74,5 & 35,62 & 5,60 & 155,56 & 27,59 & 33,22 \\
\hline Corridor & 35 & 75 & 49,8 & 16,44 & 13,33 & 77,92 & 40,74 & 20,30 \\
\hline Chamber & 40 & 180 & 89,2 & 43,30 & 2,25 & 40,00 & 14,73 & 9,02 \\
\hline Cellar & 43 & 60 & 54,3 & 24,53 & 5,97 & 14,81 & 10,39 & 4,42 \\
\hline Stairs & 60 & 75 & 65,0 & 28,80 & 6,25 & 50,00 & 23,46 & 19,04 \\
\hline Entrance & 40 & 60 & 43,3 & 16,66 & 2,35 & 7,50 & 4,69 & 1,84 \\
\hline
\end{tabular}


It can be summarized that in inhabited rooms incl. living room and even bedroom the illuminance in the middle of unobstructed area is about 100 Ix. However, variation expressed by the standard deviation is relatively high and low illuminance of about only $40 \mathrm{Ix}$ can be found in many rooms of that kind. It is interesting that similar average values are measured for other room types as well, like kitchen, bathroom and corridor. At some local places the measured illuminance is different, e.g. in the middle of the work desk in kitchen it is more than $150 \mathrm{~lx}$.

Table 4 shows results of the investigation of installed power. The presented results are not yet related to the technology involved, further analyses are needed in this aspect. Nevertheless the data give imagination on the average installed power and specific installed power (related to the useful area) $P_{\text {av }} / A$. Specific installed power is around $8-10 \mathrm{~W} / \mathrm{m}^{2}$ for most of rooms. Smaller is the value for stairs and more power demanding rooms comprise bathrooms, toilets and cellars where still incandescents can be obviously found. Comparing the Tables 4 and 2 it can be concluded that there is generally good correlation between benchmark values in the draft standard and the research results. Supporting by further analyses and data from more questionaires the benchmark values can be slightly adjusted.

Installed power of flats varies between 200 and $2600 \mathrm{~W}$, the average is $900 \mathrm{~W}$. This figures can be used to estimate the share of lighting on total energy consumption of residential buildings.

\section{Conclusions}

The lighting practice requests for a standard on home lighting. This can be understand as a reason to update the current national standard and to bring it to the level of knowledge and available technology. But for the solution itself, including the decorative aspect, should be given freedom.

The questionaire-based investigation is expected to provide a vast of useful information on home lighting in Slovakia, which is assumed to be applicable for any other European country. Results presented in this paper must be taken as first and interim. To achieve reliable data it is necessary to collect yet more questionaires what is time consuming and mostly a volunteer work. While collecting further questionaires, work on the topic continues with preparation of evaluation tables for individual parameters and then evaluation of the correlation between different parameters. After collection of harvested data and their evaluation, these will be presented on conferences and published in journals. Results of investigation will be used for the standardization of home lighting requirements.

Also extension of the standard EN 15193 on home lighting is meaningful and should not be excepted from assessment of energy perfomance in residential buildings. The last known draft of the standard prEN 15193-1 includes few basic normative requirements for domestic lighting like the standard annual operation time, installed power in different kinds of rooms and useful area of these rooms. The standard is, however, oriented to energy performace.

Photometric aspects are partially dealt in the second part which has status of technical report and includes also guides to good home lighting. Because the second part is not a standard, there are no photometric requirements. Inclusion of home (or domestic) lighting is anyway a big step forward and a good starting point for future extension of the topic, possibly in a self standing European standard.

\section{Acknowledgements}

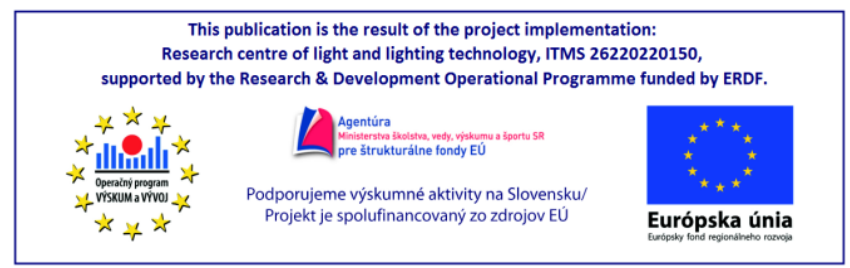

\section{REFERENCES}

[1] STN 36 0452:1986 Artificial Lighting of Residential Buildings

[2] STN 36 0450:1986 Artificial lighting of Interiors (withdrawn)

[3] STN 73 0580-2:2000 Daylighting of Residential Buildings

[4] STN EN 15193:2008 Energy performance of buildings. Energy requirements for lighting

[5] prEN 15193-1:2014 Energy performance of buildings - Module M9 - Energy requirements for lighting - Part 1: Specifications

[6] VanBommel, W. and VanDyk, J.: Security lighting for domestic exteriors. Proceedings of the IESNA Annual Conference, St. Louis (1984)

[7] Banwell, P., Brons, J., Freyssinier-Nova, J.P., Rizzo, P., Figueiro, M.: A demonstration of energy-efficient lighting in residential new construction, Lighting Res. Technol. 36,2 (2004) pp. 147-164

[8] Van Tichelen, P.: Preparatory Studies for Eco-design requirements of EuPs - Final report - Lot 19: Domestic lighting, 2009, 657 p., http://www.eup4light.net/

[9] Bodart, M., Roisin, B., Deneyer, A., D'Herdt, P.: Establishment of innovation guidelines for the residential lighting from a relighting project. Lux Europa 2009, 8-10 september 2009, Istanbul, Turkey, $8 \mathrm{p}$

[10] Deneyer, A., D'Herdt, P.; Roisin, B., Bodart, M.: The use of energy efficiency in dwellings - Challenges and potential. Lux Europa 2009, 8-10 september 2009, Istanbul, Turkey, 8 p.

[10] Gasparovsky, D., Raditschova, J.: Home Lighting. Svelto 2013, Podbanske, Slovensko, 23-25 October 2013, pp 195205

\section{Authors:}

Doc. Ing. Dionýz GAŠPAROVSKÝ, PhD., Slovak University of Technology, Faculty of Electrical Engineering and Information Technology, llkovicova 3, 81219 Bratislava, Slovakia, e-mail: dionyz.gasparovsky@stuba.sk Ing. Jana RADITSCHOVÁ, PhD., Slovak University of Technology, Faculty of Electrical Engineering and Information Technology, llkovicova 3, 81219 Bratislava, Slovakia, e-mail: raditschova@stuba.sk 